Molecules 2001, 6, M269

\title{
2-Cinnamyl-1,3-oxazole-4-carboxaldehyde p-Toluenesulfonyl Hydrazone
}

\section{Fahim Ahmed}

Department of Chemistry, Marquette University, P O Box 1881, Milwaukee, WI 53201-1881, USA

E-mail: fahim100@yahoo.com

Received: 27 October 2001 / Accepted: 15 December 2001 / Published: 20 December 2001

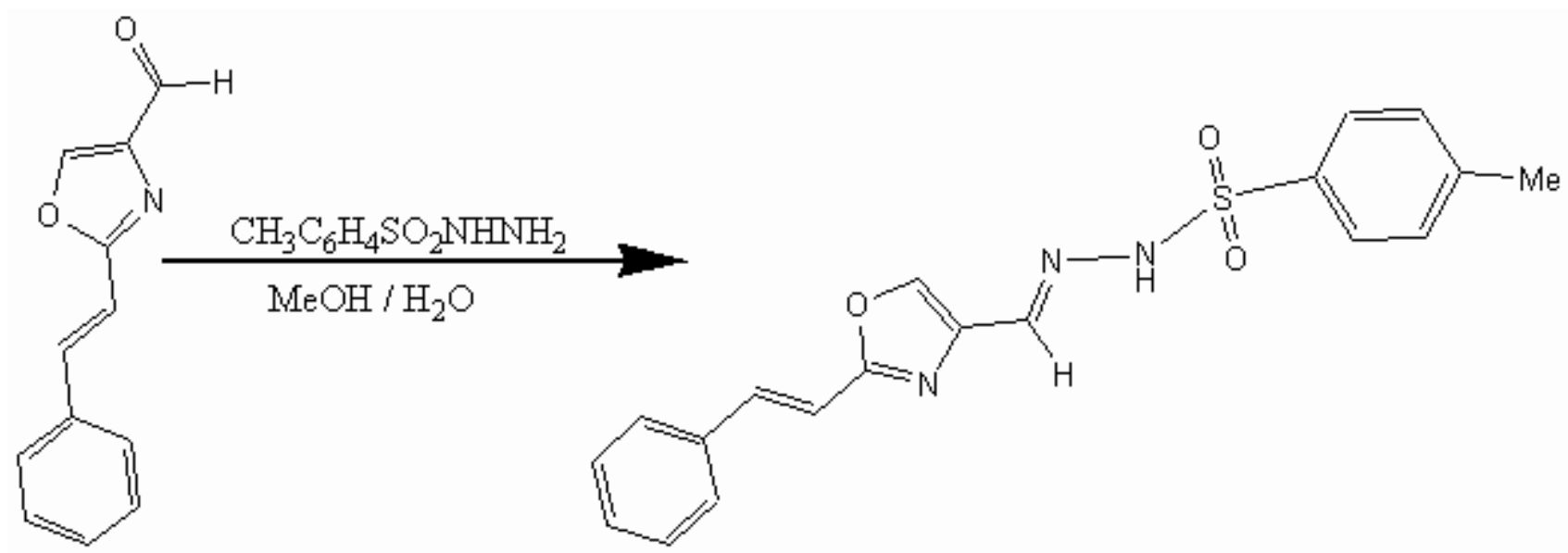

To a stirred solution of p-toluenesulfonhydrazide $(0.61 \mathrm{~g}, 3.3 \mathrm{mmol})$ in methanol/water $(6: 4,20 \mathrm{ml})$ at $60^{\circ} \mathrm{C}$ was added 2-cinnamyl-1,3-oxazole-4-carboxaldehyde [1] $(0.50 \mathrm{~g}, 2.5 \mathrm{mmol})$. The solution was cooled to room temperature and stored in the refrigerator overnight. The precipitate which formed was collected by filtration and washed with methanol/water mixture $(6: 4,10 \mathrm{~mL})$ to give 2-cinnamyl1,3-oxazole-4-carboxaldehyde p-toluenesulfonyl hydrazone as a colorless solid (0.66 g, 72\%).

M.p. $177-179^{\circ} \mathrm{C}$.

${ }^{1} \mathrm{H} \mathrm{NMR}\left(\mathrm{CDCl}_{3}\right): 12.04(\mathrm{~s}, 1 \mathrm{H}) ; 7.93-7.82(\mathrm{~m}, 3 \mathrm{H}) ; 7.64-7.62(\mathrm{~m}, 3 \mathrm{H}) ; 7.46-7.43(\mathrm{~m}, 3 \mathrm{H}) ; 7.42-7.34(\mathrm{~m}$, $3 \mathrm{H}) ; 6.90(\mathrm{~d}, \mathrm{~J}=16.7,1 \mathrm{H}) ; 2.42(\mathrm{~s}, 3 \mathrm{H})$.

${ }^{13} \mathrm{C} \mathrm{NMR}\left(\mathrm{CDCl}_{3}\right): 163.0,144.7,139.0,138.9,137.3,136.0,135.3,129.9,129.8,129.5,128.9,127.8$, 127.4, 114.4, 21.4.

IR (neat): $\mathrm{n}_{\max } 3149,2934,2919,1716,1648,1060,962,805 \mathrm{~cm}^{-1}$.

Anal.calc. for $\mathrm{C}_{19} \mathrm{H}_{17} \mathrm{~N}_{3} \mathrm{O}_{3} \mathrm{~S}$ (367.43): C 62.11, H 4.66, N 11.44; found: C 62.15, H 4.73, N 11.26.

Acknowledgment: The Financial support of the National Institute of Health (GM-42641) and the Marquette University Graduate School is acknowledged. The author would like to thank Dr. William A. Donaldson (E-mail: william.donaldson@marquette.edu) for his encouragement.

\section{Reference}

1. Evans, D.A.; Fitch, D. M.; Smith, T. E.; Cee, V. J. Application of Complex Aldol Reactions to the total Synthesis of Phorboxazole B. J. Am. Chem. Soc. 2000, 122, 10033-10046.

Sample Availability: Available from the author and from MDPI. 
(C) 2001 MDPI. All rights reserved. Molecules website http://www.mdpi.org/molecules/ 